\title{
Evidence of a dense water vein along the Libyan continental margin
}

\author{
G. P. Gasparini ${ }^{1}$, A. Bonanno ${ }^{2}$, S. Zgozi ${ }^{3}$, G. Basilone ${ }^{2}$, M. Borghini ${ }^{1}$, G. Buscaino ${ }^{2}$, A. Cuttitta ${ }^{2}$, N. Essarbout ${ }^{3}$, \\ S. Mazzola ${ }^{2}$, B. Patti ${ }^{2}$, A. B. Ramadan ${ }^{3}$, K. Schroeder ${ }^{1}$, T. Bahri ${ }^{4}$, and F. Massa ${ }^{4}$ \\ ${ }^{1}$ CNR - ISMAR, Sezione di La Spezia, Italy \\ ${ }^{2}$ CNR - IAMC, Sezione di Mazara del Vallo, Italy \\ ${ }^{3}$ Marine Biology Research Centre (MBRC), Tajura, Libya \\ ${ }^{4} \mathrm{FAO}$ - MedSudMed Project, Rome, Italy
}

Received: 21 November 2007 - Revised: 14 December 2007 - Accepted: 19 December 2007 - Published: 4 February 2008

\begin{abstract}
For the first time it was possible to investigate a still poorly known region of the eastern Mediterranean Sea, the Libyan continental margin. An oceanographic cruise, performed during summer 2006, revealed an important and novel feature: a dense vein flowing along the continental slope. The paper describes the vein evolution with some insights on its dynamic and furnishes an estimate of its transport, which results to be comparable with the Adriatic Deep Water production rate. The cascading into a steep canyon which incises the continental shelf suggests that the vein may play an important role in ventilating the deep layers of the Ionian Sea.
\end{abstract}

Keywords. Oceanography: general (Continental shelf processes) - Oceanography: physical (Currents; Hydrography)

\section{Introduction}

Sources of dense water formation are found mainly in the polar regions or in proximity of enclosed seas where evaporation contributes to increase the density of the resident water masses, as is the case of the Mediterranean Sea. The descent of dense water from the continental shelves into the deep ocean over the continental slope is an important component of the thermohaline circulation. In the Mediterranean Sea several dense veins, flowing along the continental margin, are known and largely investigated. Their role is of primary importance for the thermohaline circulation of the Mediterranean Sea and for the ventilation of the deep layers. In the Adriatic Sea a dense vein, produced in the very shallow northern part, flows along the Italian coast and reaches the Ionian Sea where it sinks at great depths (1500-2000 m or more). In the Gulf of Lions coastal dense water is present, which reaches higher depths cascading down several canyons

Correspondence to: G. P. Gasparini

(gasparini@sp.ismar.cnr.it) along the continental slope (Canals et al., 2006). The main purpose of this work is to show a further dense vein never detected before, flowing along the Libyan continental margin.

The thermohaline characteristics and the water mass circulation along the Libyan coast are poorly known. The very few available information permit only a coarse description of the hydrographic conditions of the region. Some vertical sections outside the continental margin (Guibout, 1987) suggest that the region has a marginal role in the east-west exchanges, with a small amount of Atlantic Water (AW) and a scarce presence of salty intermediate water. In the deep layer, close to the bottom, a colder and denser signature can be observed during winter and summer.

The classical Mediterranean circulation schemes (Ovchinnikov, 1966) agree in indicating a prevalent anticyclonic circulation, both in the surface and deep layers. From those schemes few information can be deduced about the surface path of the AW along the African coast, which generally moves from west to east, as suggested by numerical simulations (Béranger et al., 2005). The same model results agree with classical features, showing an anticyclonic circulation far from the coast, both for the surface and the sub-surface layers.

The presence of a dense vein along the continental margin and its cascading towards deeper layers could play a crucial role for the region and presumably for the entire eastern Mediterranean circulation, since it contributes to ventilate the deep Ionian Sea.

In the following, besides giving an overall description of the region, we focalize our attention on this dense water vein, which flows along the continental margin. A description of its characteristics in terms both of hydrography and of velocity is developed. The physical dynamics of the vein and, more specifically, its evolution considering the bottom stress, the pressure gradient and the entrainment with the resident water are investigated. An estimate of its transport is given together with a discussion on its possible relevance in the

Published by Copernicus Publications on behalf of the European Geosciences Union. 


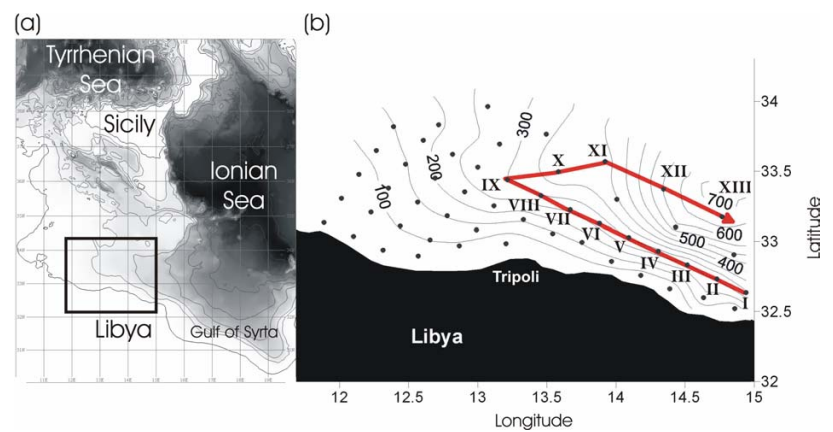

Fig. 1. (a) Sicily channel and western Ionian Sea. The rectangle delimits the investigated region; (b) detailed cruise map. Dots indicate the CTD and LADCP stations. The red line indicates the main trajectory of the vein. Roman numbers indicate the stations along the main trajectory.

Ionian and, more widely, in the eastern Mediterranean. Finally, hypothesis on its origin will be envisaged.

\section{Data and methods}

In August 2006, in the framework of the FAO MedSudMed Project, an oceanographic survey has been carried out on the western continental margin of the Libyan coast (Fig. 1a) on board the CNR research vessel Urania. A detailed grid of 61 hydrographic profiles covered the region (Fig. 1b). In all the hydrological stations, continuous vertical profiles of conductivity, temperature, pressure and dissolved oxygen were obtained from the surface to the bottom by means of a CTD SBE 911 plus probe. The probe was calibrated before and after the cruise at the NURC (NATO Undersea Research Centre) in La Spezia, Italy. Simultaneous vertical profiles of horizontal current have been acquired using a lowered ADCP system (LADCP). All data have been processed using SBE standard software for the hydrographic data, while currents are computed applying the LDEO processing software, developed by Visbeck (2002).

\section{Hydrographic characteristics of the region}

The Libyan coast is generally smooth, while the bottom topography along the continental margin is characterized by an almost flat region. The latter has a wide extension in the Gulf of Syrta (approximately $80 \mathrm{~km}$ ), which slightly reduces moving westward (Fig. 1a), but significantly expands towards Tunisia. Along the continental margin several canyons can be observed, with the most pronounced positioned in front of Tripoli. These topographic characteristics are particularly important because they intensely interact with the coastal current, as we will discuss in the following. The horizontal map of the salinity minimum $\left(S_{\min }\right)$ evidences a westward intrusion of fresher water along the coast (Fig. 2a), with the core at about $50-70 \mathrm{~m}$ depth. Its presence is well defined on the western side, while it becomes very thin moving eastward. The $S_{\min }$ distribution evidences several fragmented structures, suggesting the interaction between two different water masses: the AW, moving eastward, and the Ionian Surface Water (ISW), which moves in the opposite direction.

The salinity maximum $\left(S_{\max }\right)$, the signature of the LIW core, shows values ranging from 38.92 to 38.71 (Fig. 2b). The $S_{\max }$ is found below $200 \mathrm{~m}$ in the deep region, while along the continental shelf it is positioned at about 160$180 \mathrm{~m}$, in agreement with the prevalence of an anticyclonic circulation in the region. Its distribution appears more regular than that of $S_{\min }$, even if some small structures may be observed, probably due to topographic effects. Salinity clearly decreases moving from east to west, confirming a prevalent westward spreading of LIW.

A major peculiarity of this region is observed below the LIW layer, related to the presence of a low temperature (Fig. 2c) along the continental slope (200-300 $\mathrm{m}$ depth). In the open sea, the same values $\left(13.5-13.7^{\circ} \mathrm{C}\right)$ are located significantly deeper $(500-600 \mathrm{~m})$. An other feature is the high salt content, with salinities generally above 38.73. Low temperature, combined with high salinity, produces density greater than 29.16, positioned along the continental margin. Outside it the same density is found at greater depths, as we can observe examining the displacement of the isopycnal 29.165 (Fig. 2d). All these characteristics suggest the presence of a dense vein, flowing westward trapped along the continental slope. A further characteristic of this water is a higher oxygen content than the surrounding LIW.

\section{Description of the vein}

Typical vertical profiles of potential temperature $(\theta)$ (Fig. 3a) in correspondence of two significant positions along the vein path (stations VI and X of Fig. 1b) show a progressive decrease of temperature from about $28^{\circ} \mathrm{C}$ at the surface to values lower than $13.6^{\circ} \mathrm{C}$ near the bottom. The salt content (Fig. 3b) evidences the AW signature with a $S_{\min }$ at about $75 \mathrm{~m}$. The successive increase reaches its maximum $\left(S_{\max }=38.89\right)$ at about $180-200 \mathrm{~m}$ (LIW core). Going deeper, a peculiar structure can be observed. At station VI, both temperature and salinity evidence a homogeneous bottom layer, about $60-70 \mathrm{~m}$ thick, with $\theta=13.56^{\circ} \mathrm{C}$ and $S=38.74$. A similar behaviour can be observed in the vertical profile of density (not shown), which reaches values close to 29.175. At station $\mathrm{X}$, located along the canyon, the vein signature is smoother, due to the higher mixing along the slope. However, at greater depth, $\theta$ and $S$ maintain almost the same values observed at station VI. Examining the structure of the horizontal velocity (Fig. 3c), a jet shape in correspondence of the bottom layer can be observed, with current speeds of about $6-8 \mathrm{~cm} / \mathrm{s}$. This jet moves following the topography: its direction is westward in station VI, that is along the continental margin, while it is 

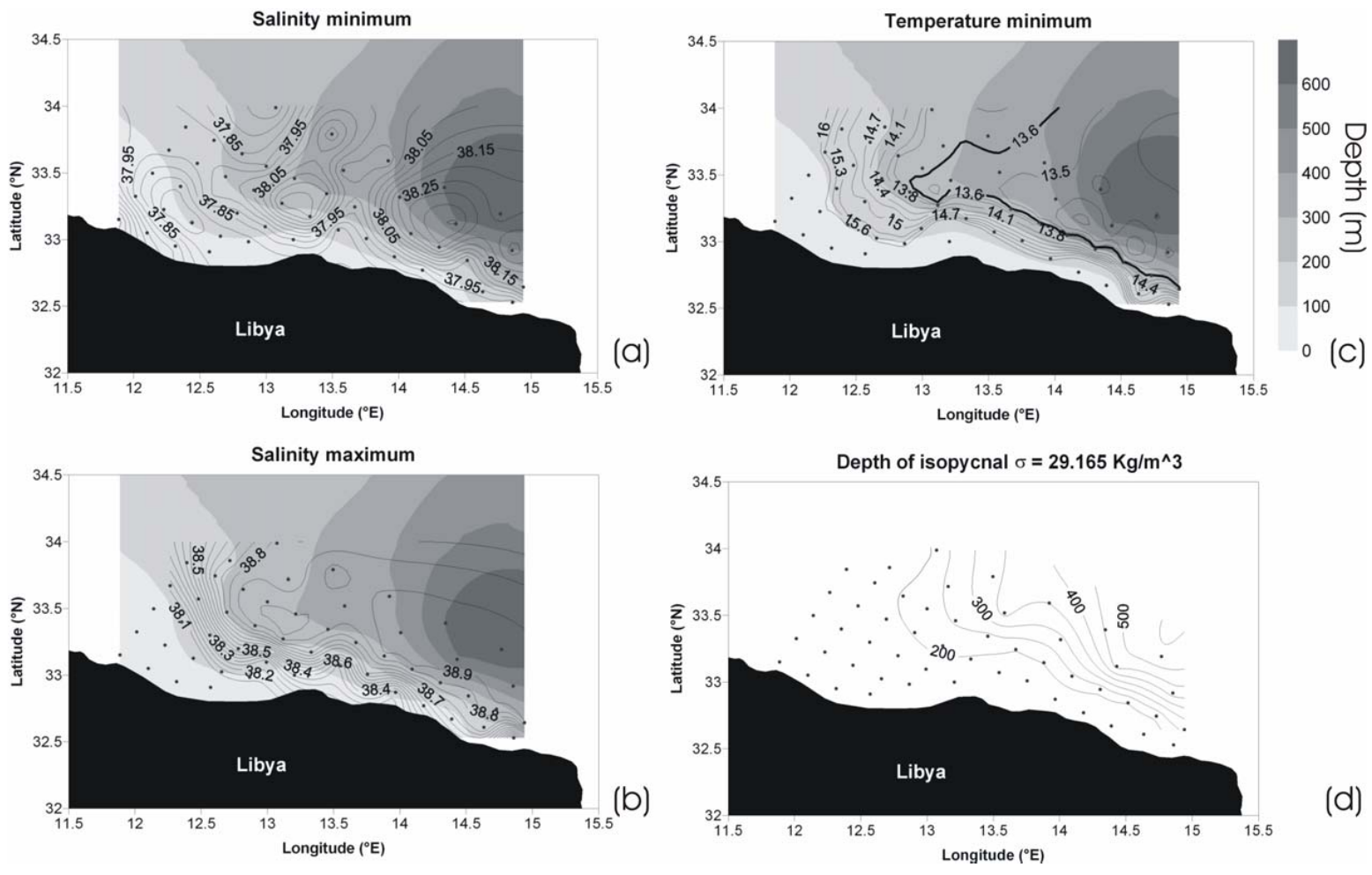

Fig. 2. Horizontal distribution of (a) minimum of Salinity $\left(S_{\min }\right)$; (b) maximum of Salinity $\left(S_{\max }\right)$; (c) minimum of Potential Temperature $\left(\theta_{\min }\right) ;(\mathbf{d})$ depth of $\sigma_{\theta}=29.165$. Grey contours indicate the bathymetry of the region.

opposite in station $\mathrm{X}$, where the vein begins to sink down to the canyon. Examining the hydrographic and dynamic characteristics for each profile, it was possible to select stations inside the vein and to track the vein trajectory (Fig. 1b). After an almost straight path, a sudden turn is observed in correspondence of $13^{\circ} \mathrm{E}$ (station IX), where a zonally oriented canyon marks the continental margin. The vein can not spread further westward and produces a cascade along the canyon, due to its high density. A new equilibrium is found at about 600-700 m depth. Unluckily, the absence of hydrographic profiles in the deeper region does not permit to follow the complete sinking of the vein. However hydrographic profiles, acquired in the Ionian interior during 2006, locate $\sigma_{\theta}=29.175 \mathrm{in}$ a depth range between 1000 and $1250 \mathrm{~m}$, which should correspond to the expected depth reached by the dense water vein in the Ionian basin.

With the available data we can describe the evolution of the vein characteristics along approximately $350 \mathrm{~km}$ (Fig. 4). Following the along-stream axis of the vein (Fig. 1b), $\theta$ and $\sigma_{\theta}$ show almost similar behaviours. Assuming the 29.16 isopycnal as the upper boundary of the vein, a detailed analysis of the evolution of its hydrographic characteristics evidences two conditions. Firstly the vein flows along the flat region and a weak increase of temperature and salinity is observed, due to the mixing with the surrounding LIW. The compensating effect of $\theta$ and $S$ maintains an almost constant $\sigma_{\theta}$. Correspondently the oxygen distribution along the vein evidences a progressive decrease from east to west, before reaching the canyon. The thickness of the vein is stable at approximately $70 \mathrm{~m}$. When the vein meets the topographic discontinuity, it is not able to maintain the same depth, its stability is destroyed and it begins to sink. Remarkable modifications, due to mixing and entrainment with the resident water, appear evident when the vein reaches depths greater than $400 \mathrm{~m}$. Temperature and salinity slightly decrease, while the vein thickness increase significantly up to $200 \mathrm{~m}$ at $700 \mathrm{~m}$ depth (station XIII).

The velocity field (Fig. 3c) evidences a well organized pattern trapped along the shelf break with a sudden change of direction in correspondence of the canyon valley. Besides these changes, its intensity maintains almost stable values, ranging between 6 and $8 \mathrm{~cm} / \mathrm{s}$.

From the available hydrographic data a mean vein width of $20 \mathrm{~km}$ can be assumed in the flat region, with a mean thickness of $70 \mathrm{~m}$. Considering an average velocity of $7 \mathrm{~cm} / \mathrm{s}$, its transport can be estimated to have an order of magnitude of $0.1 \mathrm{~Sv}$, an amount which is comparable to the ADW outflow rate from the Southern Adriatic (Manca et al., 2002). Going to examine the historical data (Gibout, 1987), they clearly evidence the presence of cold and dense water in the deep basin (about $1000 \mathrm{~m}$ depth) in front of Tripoli. This signature suggests that the vein detected during summer 2006 is 
(a)

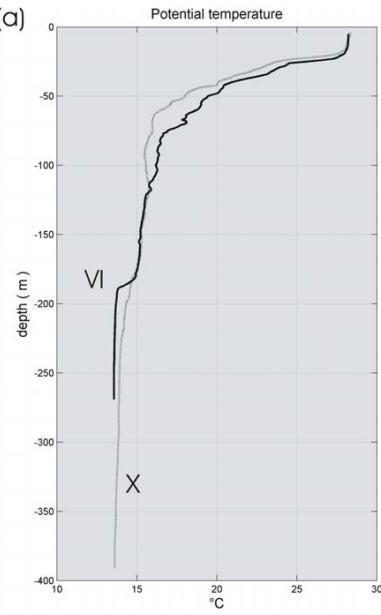

(b)
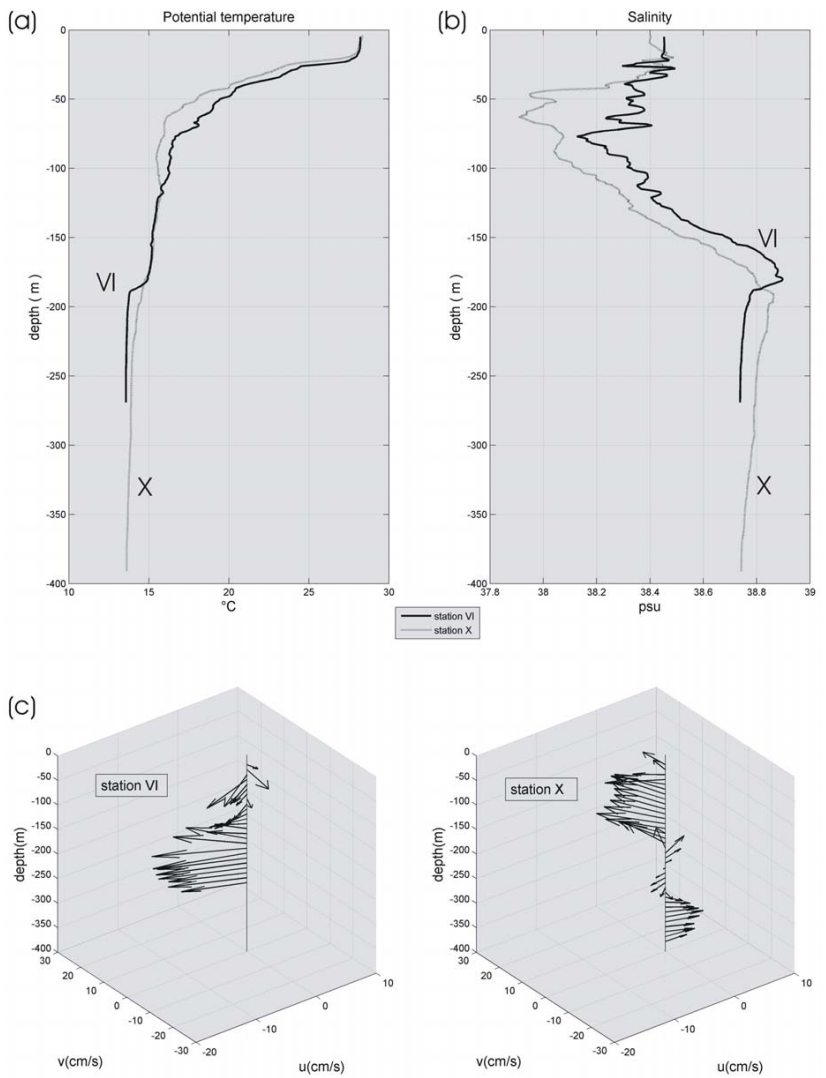

Fig. 3. Vertical structure of the vein in correspondence of stations VI and X of Fig. 1b. (a) Potential Temperature, (b) Salinity, (c) Current Velocities.

not episodic and confirms its buoyancy equilibrium in the Ionian basin at about 1000-1250 m depth, which correspond to the transitional Eastern Mediterranean Deep Water layer.

\section{Elements of vein dynamics}

Starting from the pioneering work of Smith (1975), several papers tried to describe the evolution of a dense vein along its path. With regard to the Mediterranean Sea, important studies have been developed for the Mediterranean outflow at Gibraltar (Price et al., 1993; Baringer and Price, 1997). Others considered the Eastern Outflow from Sicily (Astraldi et al., 2001) and the Adriatic outflow from Otranto (Bignami et al., 1990). All these investigations assume a stationary condition for the vein and focalize their attention on the evolution of some specific parameters along its path. The most characterizing feature is the balance between the acceleration due to the pressure gradient along the stream and the retarding effect related to stress conditions, due to interactions with the bottom and the entrainment of surrounding waters.

For this analysis we followed the formulation given by Price et al. (1993). Considering a stationary situation, we estimate the evolution of the pressure gradient along the vein
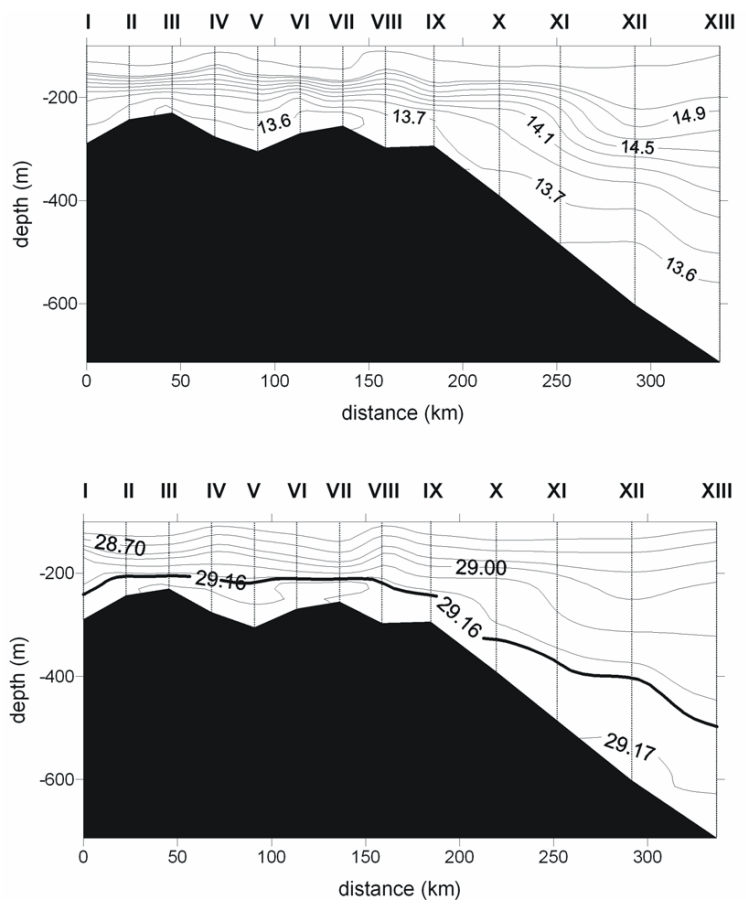

Fig. 4. Vertical section along the vein trajectory indicated in Fig. 1b. (a) Potential Temperature; (b) Potential Density.

path, together with the bottom and the entrainment stresses. According to Price et al. (1993), the pressure gradient can be written as $P_{x}=g\left[(\Delta \rho h)_{x}+\Delta \rho d_{x}\right]$, where $g$ is the acceleration of gravity, $\rho$ is the density of the vein, $d$ is the bottom depth and the derivative $x$ is taken along the vein path. The first term on the right-hand-side represent the pressure gradient related to the density variation (baroclinic term), while the second accounts for the depth variation (topographic term). The pressure gradient is balanced by the stress terms. The bottom stress, in its quadratic form, is $\tau_{b}=\rho C_{D} U^{2}$, where $\rho$ is the density near the bottom, $C_{D}=3 \times 10^{-3}$ the bottom drag coefficient, $U$ the vein velocity near the bottom. The entrainment stress can be expressed as $\tau_{E}=\rho E^{*}(U-V)^{2}$ where $E^{*}$ is the entrainment parameter, $U$ is the average alongvein fluid velocity and $V$ is the environment velocity. A parameter, which gives important information of the relevance of the entrainment, is the Froude number $F=\frac{U}{\sqrt{g^{\prime} h}}$, where $g^{\prime}=g \Delta \rho / \rho_{0}$ is the reduced gravity. $F$ is a typical hydraulic parameter that gives a measure of vertical stability and indicates whether the flow is laminar or turbulent. Entrainment is enhanced for $F>1$ and reduced for $F<1$.

In our case the vein initially flows along an almost constant depth and is mainly driven by the anticyclonic large scale circulation. Even if its cascading begins after about $180 \mathrm{~km}$, we examine its evolution along the entire path, in order to better characterize its dynamics. The pressure force per unit area along the direction of the flow is estimated to vary from very low values of about $0.2 \pm 0.1 \mathrm{~Pa}$, before the cascading 
into the canyon, to higher values during the sinking (about $1.4 \pm 0.7 \mathrm{~Pa}$ ). The along-stream slope of the bottom topography is typical of a continental shelf between stations I and IX $\left(1.8 \times 10^{-3}\right)$, where also the rate of change of the layer thickness is similar $\left(1.2 \times 10^{-3}\right)$. After station IX the two gradients increase significantly, with the flow crossing the steeper continental slope, to values of about $4.2 \times 10^{-3}$ and $2.7 \times 10^{-3}$, respectively. The topographic component, almost negligible when the vein does not change its depth, starts to get significant after the cascading of the vein. The baroclinic term, which is related to the density gradient, is almost stable in the flat region and increases when the vein sinks. However during the sinking the topographic term prevails.

The pressure force if unbalanced by a stress, would cause the flow to accelerate from about $8 \mathrm{~cm} / \mathrm{s}$ at station I above the shelf to about $16.5 \mathrm{~cm} / \mathrm{s}$ at station XIII inside the canyon. Since no such acceleration is observed, the retarding parameters are examined. The prevailing effect is due to the bottom stress $(0.02 \pm 0.01 \mathrm{~Pa})$, as confirmed by the current decrease close to the bottom (Fig. 3c) and the well mixed water inside the vein, where vertically homogeneous temperature, salinity and density are observed. To assess the entrainment parameter, several methods has been tried by different authors, addressing either mass or salt conservation (Baringer and Price, 1997; Turner, 1986). Generally for subcritical flows, as is our case (Froude number is always close to 0.4 or less), entrainment is rather small. Nevertheless, the observed increase in thickness of the vein might suggest a certain amount of entrainment. To estimate the entrainment stress, as a further retarding parameter we use the estimates made by Astraldi et al. (2001) for the Sicily Channel $\left(E^{*}=10^{-4}\right)$. The entrainment stress appears generally reduced: its mean value, $(9.3 \pm 4.6) \times 10^{-5} \mathrm{~Pa}$, is about two orders of magnitude lower than the mean bottom stress, suggesting that the accelerating effect is principally balanced by the bottom stress along the whole trajectory of the vein.

\section{Conclusion and discussion}

For the first time a hydrographic survey has been carried out on the western Libyan shelf in summer 2006. The few collected data have evidenced a dense vein flowing along the continental margin and then cascading into a deep canyon that incises the continental platform in front of Tripoli. The hydrographic data permitted to describe the displacement along the coast of typical Mediterranean waters (AW, ISW and LIW) moving in opposite directions. Besides the presence of these well known water masses, a cold and dense vein was observed. The vein, never detected or foreseen before, flows along the continental slope at about 250-300 m depth and the investigated region corresponds to its final journey before it cascades. Its dynamic is generally slow (the speed does not exceed $10 \mathrm{~cm} / \mathrm{s}$ ) with a weak entrainment, especially when the vein flows above the almost constant depth. The en- trainment becomes significant when the vein is forced to sink at higher depths due to a topographic discontinuity and its thickness increases from $70 \mathrm{~m}$ to $200 \mathrm{~m}$. The bottom stress has a prevailing effect, as evidenced by the current profile which shows reduced velocities near the bottom and the well mixed vein interior.

The transport estimate of $0.1 \mathrm{~Sv}$ suggests certain relevance in the Ionian basin. If we consider a slow erosion of the vein, due to the close contact with the surrounding LIW, and several smaller valleys along the Libya continental slope which probably are responsible for additional vein cascades along the continental slope, the computed value might be underestimated. In any case it has the same order of magnitude of the ADW production rate as reported by previous studies (Poulain et al., 1996; Manca et al., 2002). Considering the stratification in the Ionian Sea, the depth where the vein should reach a buoyancy equilibrium is around $1000 \mathrm{~m}$ depth. For these reasons the vein may have a role in determining the characteristics of the layer below the LIW.

For what concerns its origin and its journey, the vein was certainly produced at the surface along the African coast as suggested by its oxygen content, which is low but even higher than that of the surrounding water. It moves westward, probably driven by the large scale circulation, which is anticyclonic in this region. If we suppose a wintertime production (i.e. February) and a constant velocity of $7 \mathrm{~cm} / \mathrm{s}$, we can estimate a journey of the order of $1000 \mathrm{~km}$, which correspond roughly to the area off the frontier between Libya and Egypt.

The paper shows the first evidence of a novel Mediterranean feature which could play a major role in the eastern Mediterranean circulation, but more detailed and extended investigations are necessary in order to better define the importance of the dense vein, its interannual characteristics, its origin and the length of its spreading path.

Acknowledgements. The cruise was carried out on board of the CNR R/V Urania and planed in the framework of the FAOMedSudMed Project. The Marine Biology Research Centre of Tajura and the Libyan Authorities are gratefully acknowledged for their collaboration and assistance before and during the cruise. We are also thankful to officers and crew who provided continuous support during sea operation. The CTD calibrations were effected at the NURC NATO Undersea Research Center of La Spezia.

Topical Editor S. Gulev thanks one anonymous referee for her/his help in evaluating this paper.

\section{References}

Astraldi, M., Gasparini, G. P., Gervasio, L., and Salusti, E.: Dense Water Dynamics along the Strait of Sicily (Mediterranean Sea), J. Phys. Oceanogr., 31, 3457-3475, 2001.

Baringer, M. O. and Price, J. F.: Mixing and spreading of the Mediterranean Outflow, J. Phys. Oceanogr., 27, 1654-1677, 1997. 
Béranger, K., Mortier, L., and Crepon, M.: Seasonal variability of water transport through the Straits of Gibraltar, Sicily and Corsica, derived from a high-resolution model of the Mediterranean circulation, Prog. Oceanogr., 66(2-4), 341-364, 2005.

Bignami, F., Salusti, E., and Schiarini, S.: Observations on a bottom vein of dense water in the southern Adriatic and Ionian seas, J. Geophys. Res., 95, 7249-7259, 1990.

Canals, M., Puig, P., Durrier de Madron, X., Heussner, S., Palanques, A., and Fabres, J.: Flushing submarine canyons, Nature, 444, doi:10.1038/nature05271, 2006.

Guibout, P.: Atlas hydrologique de la Méditerranée, Ifremer et S.H.O.M., Brest, 1987.

Manca, B. B, Kovačević, V., Gačić, M., and Viezzoli, D.: Dense water formation in the Southern Adriatic Sea and spreading into the Ionian Sea in the period 1997-1999, J. Mar. Syst., 33-34, 133-154, 2002.
Ovchinnikov, I. M.: Circulation in the surface and intermediate layers of the Mediterranean, Oceanology, 24, 168-173, 1966.

Poulain, P.-M., Gačić, M., and Vetrano, A.: Current measurements in the Strait of Otranto reveal unforseen aspects of its hydrodynamics, EOS Transactions, AGU 77(3), 345-348, 1996.

Price, J. F., Baringer, M. O., Lueck, R. L., Johnson, G. C., Ambar, I., Parrilla, G., Cantos, A., Kennelly, M. A., and Sanford, T. B.: Mediterranean Outflow Mixing and Dynamics, Science, 259, 1277-1282, 1993.

Smith, P. C.: A streamtube model for bottom boundary currents in the ocean, Deep Sea Res., 22, 853-873, 1975.

Turner, J.: The effect of hydraulic resistance in the down-break problem, Proc. Roy. Soc. London, 227A, 399-407, 1986.

Visbeck, M.: Deep velocity profiling using lowered acoustic Doppler current profilers: Bottom track and inverse solutions, J. Atmos. Ocean. Technol., 19(5), 794-807, 2002. 